\title{
Los niños y las niñas, isujetos políticos?: construcciones posibles desde la escuela y el aula*
}

\author{
Children, Political Subjects?: Possible Constructions from School and the Classroom
}

\author{
Nesly Constanza Peña Forero ${ }^{1}$
}

Para citar este artículo: Peña, N. C. (2017). Los niños y las niñas, ¿sujetos políticos?: construcciones posibles desde la escuela y el aula. Infancias Imágenes, 16(2), 228-241.

\section{Resumen}

El presente artículo muestra un panorama concerniente a la forma como se establece la configuración de subjetividades, más específicamente de subjetividad política en niños y niñas. Se realiza un rastreo del concepto que de infancia y niño(a) se ha consolidado socialmente para entender de qué manera se asume este individuo como sujeto en una época más actual. Desde esta perspectiva, se da una mirada a la escuela como uno de los escenarios que influye en la configuración de subjetividades, para enunciar algunas de las dinámicas que allí se desarrollan en pro de la construcción de subjetividad política.

Palabras clave: infancia; escenario; subjetividad; sujeto político; escuela.
Recibido: 01-julio-2017 / Aprobado: 12-septiembre-2017

\begin{abstract}
This article shows a panorama concerning the way in which subjectivities are set up, more specifically of political subjectivity in boys and girls. A tracing of the concept of upbringing and child, has been established socially, to understand how this individual is assumed as a subject in a more current era. From this perspective, one looks at the school as one of the scenarios that influences the configuration of subjectivities, to enunciate some of the dynamics that there are developed in favor of the construction of political subjectivity.
\end{abstract}

Keywords: childhood; stage; subjectivity; political subject; school.

\footnotetext{
* Este artículo forma parte de la tesis de maestría titulada La enseñanza de la historia y la construcción de subjetividad política de niños y niñas de básica primaria (2015), de la Universidad Pedagógica Nacional. Bogotá, Colombia.

1 Magíster en Educación, Universidad Pedagógica Nacional. Licenciada en Educación Infantil. Docente de Básica Primaria, Secretaria de Educación de Bogotá (SED). Correo electrónico: nelcosp@hotmail.com
} 


\section{Introducción}

La construcción de subjetividades es un tema que se abre paso dentro de la dinámica académica, educativa y escolar. Pensar en la configuración del sujeto es la inquietud, preocupación y tema de investigación que genera diversos interrogantes que abren las puertas a múltiples formas de análisis en escenarios como la educación y la pedagogía. Desde esta perspectiva, es a partir de la escuela donde se establecen construcciones que permiten de una u otra manera aportar en la formación de sujetos y subjetividades. Por tanto, se puede hablar de estos dos aspectos desde diferentes perspectivas; desde lo social, lo cultural, lo político. Para este caso haré énfasis en la construcción de subjetividad política de niños y niñas, desde un escenario social, educativo y la práctica escolar.

Es entonces desde la práctica escolar donde se realiza este trabajo de investigación a través de un ejercicio de indagación con docentes y estudiantes de los grados primero, segundo y tercero de primaria de un colegio distrital, de la ciudad de Bogotá, ubicado en la localidad de Usme. El colegio atiende población que viene de sectores rural y urbano de la localidad de estrato socioeconómico 1 y 2 ; trabaja con los niveles de transición a grado noveno. Esto ocurre porque es un colegio pequeño que no cuenta con la infraestructura suficiente para atender la educación media en su totalidad. Los niños y niñas objeto de este trabajo de investigación se encuentran entre los 7 y 10 años.

A través del área de Ciencias Sociales y su propuesta curricular, se hace análisis a diferentes propuestas didácticas y metodológicas que se desarrollan en el aula; teniendo en cuenta diferentes concepciones que establecen tanto estudiantes como docentes sobre las temáticas presentadas. Sin embargo, este aspecto será abordado más adelante.

El niño y la niña son actores que desde el campo educativo se constituyen como sujetos $y$, para este caso, serán los sujetos de investigación asumidos como seres sociales, históricos y políticos. Así mismo, se proyectan como sujetos constituidos desde un marco cultural que les confiere ciertas características y condiciones con las cuales forjan de manera directa o indirecta su subjetividad y, por ende, su subjetividad política. Sin embargo, para ahondar en este tema resulta fundamental abordar al niño y la niña desde el concepto mismo; pero, además, situar el tema de la infancia y la niñez, haciendo un rastreo del origen de su configuración.

\section{Breve abordaje histórico sobre el con-} cepto de infancia

Es posible señalar a Philippe Aries (1987) como pionero en la investigación acerca de las características de esta categoría. Dichas investigaciones posicionaron a la infancia como un producto histórico moderno, es decir, una figura reciente. Este autor logra vislumbrar el lugar del niño y la representación social que lo configuraba como tal, sus características y la transformación que se va dando de este individuo hacia una concepción más moderna como la infancia.

Para el autor, la infancia era concebida en la edad media como la primera edad de la vida, una etapa sin mayor relevancia sujeta simplemente a la asistencia y sin ningún interés social; por tanto, su lugar en la familia y la sociedad no era relevante. Se consideraba la niñez como una cosa graciosa y divertida, donde no representaba mayor atención. Para esta época se denota un desinterés total sobre el infante, entendiendo este término como no hablante; su infancia estaba catalogada hasta los siete años, a partir de ahí ya era tratado como un adulto en miniatura, apto para aprender y formarse (Aries, 1987).

Siguiendo con los planteamientos de este autor, se establece la infancia como una construcción social que permite ubicar al niño(a) en una etapa de vida con determinadas características, con ella surge un nuevo sentimiento en que se da a este individuo un lugar diferente dentro de la familia y sociedad en general. El niño pasa de ser visto como un adulto-pequeño que necesita ser educado, para este fin se requiere de otros escenarios que ayuden a contrarrestar dicha labor como la escuela.

Esta percepción empieza a cambiar a finales del siglo XV e inicios del XVI, donde la figura del niño empieza a tener más relevancia dentro de la representación de las edades de la vida. Su condición es fijada bajo la denominación de minoría de edad donde se ubica al niño por no estar en capacidad de responder por sí mismo sin la tutoría de 
un adulto. Estas denominaciones de menor de edad y mayor de edad se ubican de manera fundamental para fijar a la población dentro de ciertas edades y así determinar sus formas de representación o participación. Bajo esta relevancia se constituye una concepción moral de la infancia. A partir de esta fundamentación moralista empieza a tener cabida un nuevo sentido de infancia, pues el niño empieza a ser objeto de atención, se debe cuidar, proteger, disciplinar y educar.

Con este nuevo sentir se asumen otras prácticas dentro de la familia y la misma sociedad para de una u otra manera regular la formación de los niños; así surge la escuela y la escolarización como práctica de disciplina que pretendía frenar las actuaciones inmorales que circulaban en las relaciones fraternas que se establecían entre el niño y el adulto. El objeto era formar hacia el buen comportamiento en sociedad y los buenos modales a través de manuales de urbanidad. Es así como el niño adquiere para esta época un interés específico dentro de la sociedad, ahora es vigilado y reprendido para ser educado.

Se da a la infancia un trato específico enfocado sobre todo en la población más pobre; esta, para Aries (1987), constituía la imagen negativa de la infancia y la sociedad. Los niños hacían parte de las calles y para evitar este desorden se crea la institución con función de hospicio, lo que deriva finalmente en la estructura de escuela, cuya finalidad era encerrar a esta población como forma de organización y estrategia de objetivación; se determina entonces la escolarización del encierro. (Martínez, citado por Jiménez, 2012 p. 21). Así, "A la luz del discurso de la pedagogía moderna la infancia se constituye escolarmente y una parte de la población es infantilizada a través del ejercicio de una relación de poder instituida en la escuela" (Narodowski, 1994, p. 59).

Esa perspectiva donde se ubicaba a la infancia como etapa de la vida predilecta para modelar al individuo desde un enfoque de formación enfatizado en la disciplina como medio de regulación, y donde la escuela juega un papel primordial como institución que permite vigilar y castigar (pero además como espacio predilecto para engendrar ciertas formas de pensamiento), sufre ciertas modificaciones donde se da un punto de quiebre y una necesidad por restablecer el pensamiento del individuo con relación a las diferentes instancias de poder. Una necesidad por reducir la emancipación y ampliar las posibilidades hacia nuevos tipos de subjetivaciones.

Este fue el interés y la apuesta de construcción social que para el momento pretendía establecer un orden dado desde la vigilancia, la disciplina y el castigo como el medio de acción que puede ser leído además en clave de lo político a partir de una estructura organizada que diera sentido a la comunidad. Esto con el fin de estructurar determinadas maneras de actuar, pensar y estar, encaminado a formas de subjetividad política que ubicarían al niño para ser figurado como un nuevo sujeto agenciado desde una connotación diferente de infancia y unos parámetros que delineaban el tipo de sujeto que se pretendía lograr.

Ahora, resulta pertinente establecer una mirada sobre el cambio que se da en el concepto de infancia a partir del discurso de diferentes modelos y corrientes pedagógicas que se establecieron en Colombia, dando una proyección diferente al escenario escolar.

\section{Nuevas configuraciones al concep- to de infancia a partir de los modelos pedagógicos}

Con la escuela tradicional se daba lugar a una infancia pasiva y vacía. Luego, en 1870, la reforma Pestaloziana modernizó la representación social de la infancia, reconociendo al niño como sujeto escolarizado en un modelo de educación liberal. En 1914 llega la escuela activa, esta recurre a la psicología y teorías del desarrollo infantil; su finalidad: acercar al individuo al aprender haciendo, de esta manera se reconoce a la infancia como categoría que establece al niño como sujeto activo que aprende en interacción con los otros y el medio que le rodea. Muñoz y Pachón (1996, citadas por Jiménez), establecen que, para la primera mitad del siglo XX en Colombia, el concepto de niñez sufre una importante transformación donde se ubican referencias directas a las cualidades del niño en el aspecto emocional, se da reconocimiento a la individualización y autonomía del niño(a) (pp. 23 y 24). 
Estos cambios instalados a partir de los diferentes modelos y teorías pedagógicas permiten dilucidar las diversas formas que ha tomado a través de la historia la categoría de niño(a) y, a su vez, el concepto de infancia en la escuela; en el cual además se configura en un escenario que le brinda a este individuo cierta legitimidad para convertirse en objeto de estudio y modelación.

Desde una visión más contemporánea, a finales del siglo XX y principios del XXI la constitución de la infancia es asumida por Jiménez (2012) a partir del problema del sujeto que está inserto en relaciones de poder y saber. De allí su idea de valorar al infante como sujeto que está inmerso en procesos de subjetivación y objetivación que se muestran como continuos, complejos e inacabados (p. 11). De cierto modo, esta visión contemporánea pretende entender la infancia desde una perspectiva más integradora donde se asume un sujeto que se construye a partir de las relaciones que establece con los agentes sociales con quienes interactúa, en cuyas relaciones se gestan aprendizajes y conocimientos que configuran subjetividades. Esta forma de entender al niño y la niña se lee desde una categoría de infancia contemporánea que involucra diversos procesos que configuran este sujeto.

Así como los diferentes modelos o corrientes pedagógicas dan un sentido diferente a la concepción de infancia, también desde un marco legal y estatal es posible plantear algunas consideraciones. Carli (2006) establece una definición de niñez dada a partir de una instancia estatal arraigada en el campo jurídico-social que ha jugado un papel muy importante en la forma de asumir como sujeto político o no al niño o niña: el de minoría de edad. Este término es asumido desde lo propuesto por Kant como: "la minoría de edad estriba en la incapacidad de servirse del propio entendimiento sin la dirección del otro" (Kant, 2010, p. 11). Este autor desarrolla una definición a partir del discurso de la ilustración, donde minoría de edad es entendida como el poco afán del hombre para hacer uso de su razón, decisión y generar su propia independencia tras haberse librado de la conducción ajena. Desde esta perspectiva, es la ilustración la salida del hombre de su minoría de edad pues hace uso público de su razón en su decisión de ser independiente.
Desde esta mirada, el término infancia estaría ligado a otros aspectos y no solo al relacionado con la edad como se establece actualmente, ya que, aunque el sujeto esté en capacidad de hacer uso de su razón, desde el marco de lo legal no es apto para tomar ciertas decisiones ni participar en determinados asuntos públicos y, por tanto, su cuidado es concedido a un adulto mayor de edad, al Estado o instituciones adscritas a este que son conformadas para tal fin.

En el siglo XX la infancia y el niño(a) escalan una posición desde una perspectiva política, jurídica y social muy relevante, en la que se establece la protección de la infancia como lucha prioritaria. Para este fin se consagra la Convención Internacional de los Derechos del Niño (CIDN), instrumento que regulará la ley para la infancia y adolescencia, aprobada en 1989. Su objetivo es consolidar al niño como sujeto de derechos, pero a partir de una instancia política, una ideología neoliberal donde el niño(a) sería capitalista, enfrentado a un Estado que debe garantizarle sus derechos (Bustelo, 2007). Esta demanda hacia la consolidación de los derechos del niño y el establecimiento de un nuevo discurso se presentan desde un panorama diferente con una urgencia por ubicar a esta población dentro de unos parámetros que cubiertos por la legalidad contribuirían a constituir un determinado tipo de sujeto idealizado desde el poder estatal.

Para el caso de Colombia se consolida una nueva infancia ${ }^{3}$ a finales de los años sesenta por medio de la Ley 75, por la cual se crea el Instituto Colombiano de Bienestar Familiar (ICBF).; Así el Estado inicia un proceso de reconfiguración de protección a la infancia, asociado a un discurso en defensa de la familia, cuyo objetivo es velar por la protección y cuidado de los niños y niñas desde el seno familiar en amparo del Estado. Esta ley permite configurar al niño(a) como un nuevo tipo de sujeto amparado bajo unos derechos. Para el 2006, se instituye la Ley

\footnotetext{
Nueva infancia: se da una nueva visión de infancia en concordancia con el reconocimiento de los derechos de los niños, a partir de estos son asumidos como sujetos de derechos (Carli, 2006, p. 21). Por tanto, su figuración en la sociedad empieza a ser más trascendente y visible. Para Postman (1982), la nueva infancia es mucho más competente en muchos ámbitos, especialmente ante algunas nuevas tecnologías con grandes habilidades (Alzate, 2002).
} 
1098 denominada código de infancia y adolescencia; esta se determina a partir de la necesidad de retomar y dar significado a la temática de desarrollo de la primera infancia. De esta manera, el sentido de infancia pasa a tener un carácter más social engranado en un marco de políticas públicas que de una u otra manera visibiliza su presencia en un escenario legal que consolida a este sujeto en una estructura de participación más amplia. En esta se señala puntualmente, de acuerdo con lo estipulado en la convención internacional sobre los derechos del niño, que deben ser reconocidos como sujetos sociales y ciudadanos en contextos democráticos. Dicha norma estipula que la primera infancia es la etapa del ciclo vital en la que se establecen las bases para el desarrollo cognitivo, emocional y social del ser humano y comprende a la población de los 0 a 6 años (Ley 1098 de 2006). De la misma manera, el código civil en su artículo 39 señala aspectos en cuanto a la edad de la siguiente manera: "se llama infante o niño aquel que no ha cumplido 7 años".

En la práctica jurídica la protección de los derechos de la infancia contemporánea ya no se basa en el discurso acerca de su situación irregular, sino en su condición de sujeto de derecho, según el nuevo paradigma de la protección integral; así la infancia contemporánea ha tomado cuerpo en el proceso de reconfiguración de la ciudad, en el discurso de la ciudad educadora, constituyéndose en el principal parámetro para medir la calidad de la democracia en las ciudades. (Jiménez, 2012, p. 20)

Es así como el concepto de infancia pasa a ser leído desde un poder judicial y legal entendido también como un sistema disciplinario y punitivo establecido como lo denomina Foucault (citado por Bustelo, 2007) a través de una "verdad administrada" (p. 115) que tiene que ver con el saber cómo poder, asociado a la gestión de justicia en defensa de unos intereses particulares. Foucault y Agamben (citados por Bustelo, 2007) plantean la infancia desde el enfoque de lo biopolítico, definido desde la regulación de los cuerpos y de la vida con la construcción de la subjetividad, en relación con el poder, lo que centra el análisis en las distintas formaciones sociales como eje de dominación y emancipación y en las formas hegemónicas que las estructuran (p. 16).

De esta manera, se ubica al niño y la niña como sujetos de derechos, se instauran como acción prevalente dentro de las políticas nacionales, se convierten en bandera de promoción y proyección en la promesa de una sociedad más justa y equitativa.

Esta configuración permite, además, agenciar un discurso donde se consideran otras connotaciones que sitúan a estos sujetos en una perspectiva de participación donde la ley les garantiza el beneficio de sus derechos, es decir, los reconoce. Esta forma de configuración trae consigo otras formas de subjetivación que a su vez determinan de cierta manera la construcción de subjetividad política al reconocerse a partir de este discurso en escenarios como la familia, la escuela y su contexto, comprendiendo que tiene derechos pero además algunos deberes.

Luego de este recorrido histórico concerniente a la connotación que se ha forjado alrededor del sentido de la infancia y por ende del niño(a), es posible entenderla como una construcción cultural por cuanto asume determinadas características de acuerdo con los intereses y necesidades de la sociedad del momento. "Se entiende a la niñez como proceso biológico abstraído de toda acción cultural por cuanto devienen de un proceso de desarrollo que estructura operaciones cognitivas, físicas y de adaptación al medio" (Narodowski, 1994, p. 29). Desde esta percepción es posible entender cómo, en un primer momento, se habla del niño(a) como individuo parte de la estructura social para luego hablar de infancia, como una construcción no solo social sino cultural que amplía su sentido y permite visualizar ya no solo un individuo sino un sujeto.

\section{Configuración de sujetos y subjetivida-} des a través de escenarios de interacción Como seres humanos poseemos unas características comunes: somos seres sociales, culturales y políticos que, permeados por el contexto y entorno de formación, apropiamos ciertas formas y maneras de asumir y leer el mundo. Desde los diferentes escenarios que allí emergen se va estableciendo una construcción de sujeto y subjetividades en un marco social legítimamente propio. 
Los niños como sujetos cobran en la actualidad una posición más relevante ante la sociedad, su formación es ahora un asunto que involucra a cada una de las instancias en las cuales tiene contacto y de las cuales extrae o apropia ciertos conocimientos y aprendizajes para su vida. Es además sujeto de derechos, los cuales deberían garantizarle bienestar y mayor participación.

Sin embargo, persisten algunos contextos en que el niño(a) es asumido como un presujeto, un sujeto en formación o un ser apolítico o en condición de preciudadanía. Como bien lo ilustra González (2012) en su artículo sobre la formación ciudadana de niños y niñas costarricenses, los niños(as) son excluidos como ciudadanos partiendo de la presunción de que ellos no son ciudadanos al ser menores de edad, más aún para el caso de la primera infancia (p. 2). Estas formas de pensamiento, afirma la autora, derivan además del ideal que tienen los adultos frente a la concepción de vulnerabilidad e incapacidad de los niños para ejercer sus derechos, de su falta de experiencia y razonamiento marcadamente egocéntrico, sustentando una imagen de sujeto pasivo, moldeable, sin voz, no racional y con pocas alternativas para concebirlo como ciudadano (pp. 4-7).

Esta concepción de preciudadano deslegitima al niño(a) como sujeto capaz, ubicándolo en una condición de fragilidad, cuando es claro que desde su primera etapa de vida este está en capacidad de crear, explorar, resolver y proponer. Su condición es la de un sujeto social que hace parte de un colectivo y que, por tanto, tiene los mismos derechos que cualquier otro. Es en esta medida el adulto quien debe protegerlo, pero validando su condición de ciudadano con voz. O como bien lo argumentan MacNaughton, Hughes y Smith, "Los niños como actores sociales tienen ideas validas, valores y comprensiones de sí mismos, los otros y de su mundo, y pueden actuar como compañeros con los adultos para desarrollar nuevas políticas y prácticas" (2007, citado por González, p. 15).

Estas categorizaciones resultan del engranaje conceptual que ha hecho parte de los modos como se ha construido el concepto de infancia en sintonía con el de minoría de edad. Así, yendo más allá de estas categorías, el niño y la niña pueden ser pensados como seres humanos que van configurando una subjetividad política a partir de los conocimientos que le son otorgados en su medio tanto social, cultural, como educativo.

Frente a esta determinación es importante hacer referencia a lo que plantea Kaufman (2006) cuando afirma que los primeros lazos afectivos son fundadores de la subjetividad porque es aquí donde el sujeto se ubica en la historia familiar y constituye su subjetividad, es decir, el niño ingresa a un proceso de alteridades que le garantizan la posibilidad de adquisiciones yoicas. De acuerdo con lo anterior, es a partir de la mediación cultural que se engrana a este individuo en la adquisición de un lenguaje, unas creencias y una forma de leer el mundo que le es más inmediato. Desde allí, y desde su ubicación como parte del mismo, adquiere la posibilidad de sentirse como parte de, identificarse con su medio y aquello de lo que él también hace parte. Vigotsky:

[...] hace referencia allí a la zona de desarrollo próximo del niño desde un campo de interacción, donde se involucra también la categoría de sentido, esta refiere una construcción histórica singular en un contexto cultural que se articula con un sentido también afectivo. (citado por Hernández, 2008, p. 152)

Es entonces el medio, la cultura, el lenguaje, las diferentes interacciones y relaciones sociales que establece el niño(a) las que le permiten conformar su estructura de conocimiento social, político, histórico y cultural.

En esencia se puede asumir al niño(a) como un sujeto que a partir de su interacción con el mundo configura su propia subjetividad. Hernández lo menciona como:

subjetividad desde el enfoque histórico y cultural se encuentra fundamentado en la complejidad, cuyos elementos giran en torno a la construcción de sentido, al sujeto como generador y constructor de ellos, y a la inclusión de la dimensión afectiva dentro de la configuración subjetiva; allí la subjetividad se establece en una relación compleja que involucra lo psicológico y lo social, en una situación dialéctica cuya naturaleza es histórica y social. (2008, p. 148) 
Dicha afirmación es sustentada desde el marxismo como bien lo enuncia Moscovisci (citado por Díaz y González, 2012) en el cual la conciencia humana solo tiene consideración desde un carácter social, estableciendo una relación entre lo individual y lo colectivo. Allí, además, se da un marco de relación entre sujeto y objeto que le permite a este sujeto ser configurado y determinado por una serie de condiciones históricas que le brindan la posibilidad de reconstruir, transformar, re-significar el mundo donde interviene. Así se va configurando al sujeto, su subjetividad y se hace tránsito a la consolidación de una subjetividad política.

Entendiendo subjetividad política como lo plantea González (entrevistado por Díaz, 2012) que determina subjetividad política como la condición del sujeto que se expresa en cuanto a sujeto político a través del ejercicio de la ciudadanía, en este sentido lo político es lo constituido desde acciones que implican tomar postura respecto a lo público, es decir, a aquello que nos es común, es entonces al tomar una postura como se configura el sujeto político. De esta manera, la subjetividad política sería una producción de la subjetividad social que da espacio a diversas formas de subjetivación.

Se puede determinar, entonces, que la configuración de subjetividad política emerge inicialmente desde estructuras que se establecen a través de las interacciones dadas en los diferentes escenarios de socialización primaria (familia, cultura, entorno) y en cuyo caso se brinda una formación a partir de estructuras discursivas dominantes. Allí, la escuela se ubicaría como otro de los escenarios que contribuye a la configuración de subjetividad política, donde se puede mencionar un trabajo dirigido al enfoque de este aspecto a través del entorno y contexto cotidiano del sujeto, mediado por las prácticas de poder que hacen parte y toman forma en todas las expresiones de la vida. Esto, en un ejercicio que busca conjugar formas de expresión, narrativas históricas como expresiones simbólicas que interpelan por una subjetividad política que dé cuenta de un sujeto autónomo y reflexivo con un sentido ético que le permita pensar en el otro. Es entonces la escuela el espacio que permite establecer otras configuraciones que refuerzan la formación de sujetos y subjetividades a través de dimensiones como lo social, político y cultural.
Este escenario creado en un inicio como medio de control y disciplina, en busca de restablecer el orden social, se consolida más recientemente como espacio que influye en la formación del individuo y lugar donde además adquiere determinadas maneras de leer el mundo, apropiar otras dinámicas que amplían la mirada hacia otras formas de pensar. Así, se asume como espacio para la construcción o re-configuración de subjetividades y subjetividad política.

\section{La escuela: otro escenario fundante} para la construcción de subjetividades y subjetividad política

Desde las diferentes dinámicas que se han desarroIlado en la escuela a través del tiempo, se han focalizado ciertos objetivos que conllevan a instaurar la razón de ser o el sentido que se le da a este espacio en una estructura social, que además es cultural y también política. Esas funciones adquiridas por la escuela se han ido modificando a través del tiempo, debido a los cambios estructurales y las nuevas necesidades que trae consigo la demanda social.

En este sentido, las prácticas educativas que se han dado en este espacio también se han modificado. No obstante, siempre con la idea de modelar un sujeto con un interés u objetivo específico. A partir de este interés o intereses se consolida una apuesta política desde la cual circulan diversas formas de subjetivación dadas, de un lado, a través de las diferentes políticas institucionales y, por otro, desde los diferentes escenarios sociales que le permiten al sujeto establecer una lectura del mundo. Es así como las diversas dinámicas desarrolladas en este escenario, junto con los actores que allí confluyen, se tejen un sin número de experiencias que hacen posible la configuración de subjetividad política.

Para abordar un poco más a fondo este aspecto es preciso señalar algunas de las actividades $y$ prácticas que se desarrollan en el aula, donde tanto estudiantes como profesores elaboran concepciones mediadas por unos aprendizajes previos, instalados a través de su experiencia de vida. Las diversas actividades que desde la escuela y el aula se desarrollan brindan posibilidades de apropiación y construcción individual y colectiva. 


\section{Una experiencia desde el aula}

Es a través del trabajo que se desarrolla en el aula con estudiantes donde es posible analizar algunas de las construcciones que ellos elaboran de aquello que se les enseña. Por tanto, y con el objetivo de establecer la configuración de subjetividad política en los niños y niñas de estos grados, se realizó un ejercicio de indagación donde se utilizaron mecanismos como la entrevista a estudiantes y docentes de los grados antes mencionados. Se hizo, además, una revisión de los planes de estudio del área de sociales que trabaja cada una de las docentes y una revisión de los cuadernos de estos estudiantes como apoyo visual de aquello que mencionan durante la entrevista.

Las entrevistas a los niños, niñas y docentes parten de unas preguntas base que permiten focalizar el diálogo que se genera entre entrevistado y entrevistador, cuyas respuestas dan paso a nuevas preguntas e interrogantes que no se encontraban planteadas para ese momento pero que fortalecen el ejercicio de indagación. Mientras se hace la entrevista los niños utilizan el cuaderno como medio de reconocimiento sobre aquellos temas vistos en el área de sociales. Sin embargo, para este caso nos centraremos tan solo en el ejercicio de análisis que se realizó a las respuestas suministradas por los estudiantes en la entrevista y la revisión que se hizo a los cuadernos de los estudiantes, que sirvió como apoyo visual durante este proceso.

Luego de la aplicación de cada una de estas herramientas, se realiza un ejercicio de transcripción, interpretación y análisis de las respuestas dadas por los estudiantes. De esta manera, se pueden establecer algunas nociones resultado de las diferentes concepciones y de aquellos conocimientos adquiridos frente a lo aprendido y comprendido, que además se configuran como ejes de aprendizaje. Es así como se tejen relaciones, apreciaciones, semejanzas y patrones de enlace o recurrencia, que hacen parte de la forma como el niño y la niña construyen su conocimiento. Estas concepciones son agrupadas en cuatro nociones que dan cuenta de la manera como estos niños y niñas construyen subjetividad política; estas se denominan: lugar social, formas de participación, identidad y relaciones con los demás.
En cada una de estas nociones es preciso señalar algunas de las temáticas que de una u otra manera establecen relaciones para determinar la manera como los niños asumen y aprenden aquello que se les provee en el aula relacionado, además, con su contexto. Como seres sociales, el niño y la niña se ubican dentro de un lugar, un contexto, un entorno y desde allí adquieren un espacio que les es propio $y$ en el cual se reconocen.

Este sentido de apropiación de alguna manera se convierte en tema de trabajo en el aula, pues de acuerdo con los parámetros establecidos dentro de los contenidos curriculares de Ciencias Sociales se plantea desde los estándares básicos de competencias el desarrollo de compromisos personales y sociales desde los cuales se pretende que el estudiante "Valore aspectos de las organizaciones sociales y políticas de su entorno que promuevan el desarrollo individual y comunitario" (MEN, 2006, p. 116).

Por tanto, se puede apreciar desde el trabajo que se desarrolla en esta área una marcada influencia hacia temas como: ¿quién soy yo?, mi familia, mi colegio, el barrio, mi país Colombia; los cuales hacen parte de la propuesta de trabajo para grado primero y segundo, este último grado complementando con temas como los símbolos patrios, las normas de comportamiento, derechos y deberes de los niños. Además de otros temas relacionados con la historia tradicional como la Independencia, la Batalla de Boyacá, la Colonia, entre otros. Para grado tercero se aprecia una propuesta desarrollada por la docente encargada de esta área, la cual hace énfasis en la formación política. Esta propuesta plantea ciertas dinámicas que conllevan a que el estudiante comprenda las diferentes formas de organización política y social, destacando conceptos como poder, Gobierno, Estado, sociedad. Es entonces a través de estas dinámicas que los niños adquieren elementos que les permiten establecer construcciones para la configuración de subjetividades; sin dejar de lado la presencia de otros espacios y dinámicas que contribuyen también a este proceso.

A continuación, se hace referencia a cada una de las nociones establecidas por los niños, resultado del trabajo de análisis de la información suministrada por ellos durante la entrevista. 


\section{Nociones establecidas por los niños \\ La construcción de identidad}

Dentro de las temáticas trabajadas en el aula, a partir de temas como: ¿quién soy yo?, mi familia, mi colegio, gobierno escolar, mi barrio, los símbolos patrios, etc., la identidad es uno de los componentes que presenta mayor relevancia a la hora de posibilitar al niño diversos elementos para que se reconozca como sujeto a partir del "yo".

Paula: Nos toca dibujar la bandera del colegio y la de Colombia, el escudo, escribir el himno de Bogotá. (Entrevista a Paula, grado segundo, 8 años)

Sergio: Vimos el colegio, las normas de comportamiento que nos dicen que debemos portarnos bien. (Entrevista a Sergio, grado tercero, 9 años)

Juan: Soy de Colombia, mi colegio se llama Brazuelos, esa es la bandera de mi colegio. (Afirmaciones realizadas por Juan en entrevista, grado segundo, 8 años)

Sergio: Patria es donde uno vive está conformada por los ciudadanos que viven en la ciudad. (Entrevista a Sergio, grado tercero, 9 años)

Es a través de esta noción que se empieza a hacer prevalente un sentido de pertenencia e identificación con algo o algún lugar, y esta forma de entendernos y asumirnos como parte de algo permite, además, comprometer formas de pensar y actuar, haciendo posible consolidar la configuración de subjetividad política con respecto a un entorno y los espacios que lo configuran. Es así como el colegio, la familia, el barrio y la ciudad se señalan como esos espacios en los cuales convergen situaciones o acciones en los que se convive diariamente, y desde donde desarrolla algunas de las formas a través de las cuales participa y establece relaciones que, a su vez, le posibilitan un lugar social, ubicando a partir de estas su razón de ser como individuo en aquellos lugares donde interactúa.

Desde esta perspectiva, es asumido el niño(a) en el escenario escolar, donde se le proyecta un panorama más amplio hacia su condición como sujeto social y político con un sentir histórico, pero también actual y cotidiano. Desde el aula este sujeto se va agenciando como un ser humano en constante construcción de su subjetividad política, a partir de las diversas interacciones que establece con sus pares, con el adulto (profesores, coordinador, con sus padres, etc.), desde las diferentes actividades que en este escenario desarrolla ya sean académicas, lúdicas; en sí, este espacio hace parte de su formación como sujeto. A partir de él se configura, apropiando un lugar que reconoce para sí mismo y que de cierta manera lo identifica. Esta construcción la establece desde las actividades cotidianas, sus costumbres, estilo de vida, desde los cuales empieza a construir una lectura del mundo.

El reconocimiento hacia sí mismo, "yo", es, como ya se dijo anteriormente, el eje de articulación para que el niño se considere como parte de una sociedad, donde es importante resaltar características, pero además comprender funciones, adoptar normas y reconocer símbolos para identificarlos y reconocernos como agentes sociales. Así mismo, cuando se hace énfasis en la denotación de cada tema como propio: "mi", se establece un referente que atribuye una singularidad a adoptar cada tema a partir de su experiencia de vida, donde se adquiere un lugar con ciertas características. A partir de estas connotaciones se empieza a adquirir un sentido de identidad.

\section{Lugar social}

Esta noción resulta de la mediación que ejerce el sujeto como ser social a través de los diferentes espacios, momentos y lugares por donde transita; desde allí se configuran diversas situaciones en las que se asigna al sujeto un lugar social. Inicialmente, este es dado a través de su cultura y entorno familiar (tradiciones, costumbres) pero luego su contexto se amplía y la sociedad le condiciona a través de ciertos preceptos establecidos. Un ejemplo de ello se da a través de los derechos y deberes que como niño o niña adquieren estos sujetos al ser parte de una sociedad desde el cual se establece un lugar social, determinado en el cumplimiento de las normas (elementos necesarios en cierta medida para establecer un orden signado en un marco hacia el buen comportamiento como finalidad para vivir mejor).

Andrés: Me han enseñado sobre el colegio, los profesores, el coordinador, la rectora, la misión, la visión; vimos derechos, deberes y que los debo aplicar 
en todos los lugares a donde vaya y actividades con mi familia. (Entrevista a Andrés, grado primero, 6 años)

Luis: Me enseñaron que hay que ser amable, obediente, juicioso, vivir en paz, feliz, en armonía y no pegarle a los demás.

Entrevistadora: ¿Y dónde hay que ser amable y obediente?

Luis: A todas partes donde vayamos. (Entrevista a Luis, grado primero, 7 años)

Paula: Que debemos hacerles caso a los papás, que hay normas en la calle, en el parque, como hacer la fila para subir al rodadero. (Entrevista a Paula, grado segundo, 8 años)

Carlos: Vimos el gobierno escolar.

Entrevistadora: ¿Y qué es el gobierno escolar?

Carlos: Es política, es la sociedad que también es política, porque la sociedad significa la política que nombra el país. (Entrevista a Carlos, grado tercero, 9 años)

Este aspecto relacionado con los derechos y deberes es una de las temáticas que se desarrolla en el grado segundo para el área de Sociales. A partir de este trabajo realizado en el aula, los estudiantes evidencian las diferentes acciones a través de las cuales establecen su participación como sujetos de derechos, pero también de deberes. Por ejemplo, en casa deben colaborar y cumplir funciones como organizar su cuarto, ayudar con algunas actividades de la casa, obedecer las normas, entre ellas no pelear, hacer sus tareas, entre otras. Es decir, su lugar social estaría sujeto al reconocimiento y cumplimiento de dichas normas que mal o bien regulan a la sociedad. Entonces, el lugar social de todo individuo implicaría el adaptar aquellas normas, para que además le permitan el libre desarrollo de una personalidad, o en cuestión, de su subjetividad política. Sería entonces pertinente hablar aquí de una categoría de socialización descrita como "configuración del sujeto y los órdenes sociales en los que este sujeto habita y se significa" (Díaz, 2009, p. 131).

Estos aspectos se resaltan claramente en la formación de estudiantes, su interés está muy ligado a establecer un énfasis claro en el correcto actuar en comunidad, el comportamiento, los hábitos, las normas y valores. Se puede decir que una de las prioridades para este momento de formación se basa en el interés por que el niño(a) comprenda cuáles son las formas adecuadas de comportarse y actuar en público, atender llamados de atención, obedecer y seguir indicaciones. Es decir, persiste el interés por educar al estudiante frente al bien y el mal, esquemas que nos ubican como sujetos dentro de una estructura social que sectoriza de acuerdo con unas formas de pensar y actuar socialmente establecidas.

Otro aspecto a través del cual se establece el lugar social está dado a partir de la noción de niño o niña y menor de edad, regulado a través de los derechos del niño. Connotación ya mencionada anteriormente que ubica al infante o menor de edad en un lugar relevante como sujeto social con una presencia más activa y significativa en el entorno político. A partir de este tema, los niños identifican que son portadores de derechos que pueden identificar a través de las diferentes actividades que realizan de forma cotidiana como asistir a la escuela, tener una familia, contar con espacios y lugares adecuados para jugar, entre otros. A través de estos escenarios y espacios los niños van apropiando un lugar en la sociedad.

\section{Relaciones con los demás}

Las relaciones que establecen los niños con los demás desde los diferentes escenarios donde intervienen como la escuela, el barrio, su familia, el parque y otros, es otro de los aspectos que se hace relevante en el proceso educativo de enseñanza aprendizaje. Desde allí se establecen diferentes formas de interacción ya sea con el adulto o sus pares, es desde estas situaciones que se pueden apreciar diversas formas de relación dadas por estos sujetos en su entorno. Resulta en este sentido importante hacer énfasis en las diferentes formas de relación e interacción que se consolida entre pares, pues aquí se vinculan otras formas de actuar, sentir y expresar. Es en estos espacios donde el juego se presenta como su forma de relación predilecta y la situación posible para implementar sus propias reglas; así, el niño construye, aprende, imita, pero sobre todo representa aquello que le es dado desde otros escenarios como la casa, 
su cultura, entorno y comunidad. Como lo menciona Caillois (1997), la palabra juego evoca una atmósfera de diversión, combina las ideas de límite, libertad e invención. Por tanto, es posible entenderlo como uno de los resortes principales, para las sociedades desde el desarrollo de las manifestaciones más elevadas de su cultura y para el individuo desde su educación moral y progreso intelectual (pp. 7 y 8 )

Luis: Nos enseñan formas de asociarnos, compartir, hacerles caso a los papás, respetar a los compañeros, tener buena convivencia. (Entrevista a Luis, grado primero, 7 años)

Paula: Hacerle mucho caso a los papás para que nos quieran... las normas para que no nos pasen cosas malas. (Entrevista a Paula, grado segundo, 8 años)

A través de los temas vistos en el aula como "mi barrio", algunos niños manifiestan que el lugar favorito es el parque, porque allí pueden jugar, hacer amigos(as) y se divierten. Otro lugar es el colegio, el cual les gusta porque les enseñan muchas cosas y tienen muchos amigos para jugar. Se puede decir que es por medio del juego, la interacción y relación con sus pares donde él o ella representan de manera más sólida aquello que su contexto le está ofreciendo. Es además el medio por el cual expresan sus sentimientos, emociones y sensaciones. De esta manera, se puede señalar esta actividad como elemento esencial dentro de su vida.

El juego sería el elemento fundamental que le permite establecer relaciones de todo tipo, ya que está presente en cada uno de los escenarios donde interviene. Desde este se elaboran construcciones mentales, sociales, individuales y colectivas, siendo parte de su esquema predilecto para establecer reglas, acuerdos y formas de negociar, a través de un lenguaje más incluyente y asequible. El juego como actividad predilecta ocupa un lugar fundamental por ser el medio natural, simbólico e innato o tal vez la herramienta ideal que tiene el niño(a) para interiorizar o exteriorizar, para expresar y entender el mundo que le rodea. Es desde su propio cuerpo y corporalidad que este sujeto manifiesta y se manifiesta.

\section{Participación}

Desde una concepción un poco más amplia, y utilizando conceptos como gobierno, la política, ciudadanía y ciudadano, se desarrolla el tema de participación; conceptos que emergen en el aula de grado tercero de primaria debido a la propuesta de trabajo de la docente para el área de Sociales. Desde esta perspectiva se establecen algunas configuraciones que llevan a los niños a apropiar estos conceptos y asumirse como ciudadanos con ciertos derechos y deberes, instancia con la cual se adquiere algún nivel de participación.

Dentro de las dinámicas por el reconocimiento de la identidad, el contexto y el entorno, es posible (y además pertinente) mediar las diferentes formas de participación que tienen los niños en el entorno donde habitan. Sin embargo, muchas de estas dinámicas se desarrollan y representan a través de las actividades que este realiza diariamente, por esto en cada escenario el niño ubica ciertas formas de participación que le son propias. Así, comprende el rol que representa en cada lugar y dimensiona la función y organización social cuando es capaz de hacer referencia a aspectos como sociedad, gobierno y ciudadano; en esta dirección se van especificando ciertos rasgos que legitiman la consolidación de la subjetividad política.

Desde el tema relacionado con las normas y los deberes, también es posible hacer mención a las formas de participación, ya que es en escenarios como la familia, la escuela, algunos lugares del barrio como la iglesia o el parque donde el niño adquiere ciertos espacios de participación al ser parte de ellos pues allí juega, se relaciona, se divierte y aprende. En su casa, por ejemplo, debe realizar ciertos deberes como organizar su cuarto, ayudar con el oficio, cumplir con las normas establecidas; situaciones que de una u otra manera lo involucran. Es así como se establecen subjetividades en el orden de lo moral y la regulación, a través de las normas como indispensables para la incidencia de buenas relaciones, donde se consolida aquello que está bien o mal, o aquello que es permitido y no permitido como asunto que, además, se perfila desde una perspectiva política, al pretender modelar determinado tipo de sujeto social que hace parte de una ciudad, un país, una sociedad con normas establecidas. 
Sergio: Las normas de comportamiento son para vivir en sociedad y en paz, respetando a los mayores, la naturaleza y los ciudadanos. (Entrevista a Sergio, grado tercero, 9 años)

Alrededor de estos procesos de interacción e intercambio se elaboran construcciones que precisamente llevan a concebir ciertos tipos de relación, ligadas a una forma también de pensamiento donde se establecería construcción de subjetividad política. Por tanto, se percibe allí una apuesta hacia la formación de un sujeto y una subjetividad política frente a una acción también política permeada por la necesidad de asumirse, por un lado, como ciudadano responsable y cumplidor de las normas y, por otro, como sujeto parte de la sociedad.

Cada una de estas nociones permite dilucidar las diferentes elaboraciones que hacen los estudiantes a partir del conocimiento suministrado en cada una de las temáticas desarrolladas en el aula por las maestras. En ellas se fundan ciertas relaciones que establecen patrones de enlace desde los cuales es posible realizar una lectura acerca de las construcciones mentales que se elaboran. Además de lo anterior, cómo a partir de estas el estudiante va configurando su subjetividad política, que tal vez para este caso no se da de forma tan evidente; pero que sí constituye para el docente la función de analizar a través de las diferentes dinámicas las construcciones posibles en el aula con los estudiantes.

\section{Para concluir}

Desde una mirada social y política, el concepto de infancia y niño(a) cuenta hoy con mayor prevalencia, lo que conlleva a ampliar la mirada hacia otras formas posibles de asumir a estos individuos desde una perspectiva más incluyente.

"Desde el campo de las disciplinas la concepción de infancia corresponde más a una organización discursiva donde los niños tienen lugar, con una función social, moral y cultural que les son ya dadas, las cuales constituyen su subjetividad" (Jiménez, 2012, p. 16). Es así como la categoría infancia toma mayor relevancia dentro del discurso académico, pero también político y social, posicionándose en un lugar que permite asumirla como objeto de interés primordial y dominio de saber que se encuentra en permanente estudio.
Estas connotaciones, dadas desde lo moral y cultural, han logrado poner a figurar a este sujeto en un orden social que en gran medida depende de las necesidades e incidencias que para el momento se establecen como intereses de orden socialmente establecidas. Es decir, este sujeto hace parte de una estructura que se debe modelar con el fin de cumplir unos establecimientos en pro de una sociedad idealizada. Sin embargo, estas formas de asumir a este individuo de alguna manera se verán limitadas frente a la realidad que determina el contexto en el cual se desenvuelven los niños y niñas y los diferentes escenarios de los que hacen parte. Ya que en muchas circunstancias la población de bajos recursos se encuentra marginada y desprotegida por el Estado, al carecer de gran parte de la atención básica que requieren, y es allí donde se quebrantan muchos de los derechos de estos individuos como sujetos sociales y además políticos.

Es entonces dentro de un marco social, legal, cultural, político e incluso económico desde el cual se puede establecer una lectura del concepto de infancia, mediada por una estructura que conlleva a cumplir determinados fines dentro de la sociedad. Sería entonces pertinente señalar la influencia y razón de ser que tiene cada uno de los escenarios en los cuales interactúan los niños como medios de construcción, legitimación, intervención y participación, establecidos dentro de un orden que legitima su "derecho" (a propósito del énfasis legal a reconocerlo como sujeto de derechos) significados además como escenarios primarios y secundarios que posibilitan la intervención de este sujeto y que además contribuyen, como ya se ha mencionado, en la configuración de subjetividades.

A partir de la configuración de infancia y por ende del concepto de niño(a) se asume a un sujeto social, pero a la vez a un sujeto político garante de derechos; desde esta premisa se establece la idea acerca de la construcción de subjetividad política a partir de las interacciones que desarroIla este individuo en cada uno de los escenarios que determinan su contexto social. Es a partir de estas construcciones, interacciones y experiencias de vida que se establecen procesos de relación que conllevan a consolidar dinámicas a través de las cuales se tejen diversas formas de aprendizaje 
como las que para este caso se plantearon como nociones establecidas por los niños en relación con la identidad, relaciones con los demás, el tema de participación y lugar social.

Cada una de estas nociones logra evidenciar algunas de las experiencias y didácticas propuestas por las docentes en el aula para el área de Ciencias Sociales. Apuestas que se plantean con unas directrices que abordan, por un lado, lo establecido en los estándares curriculares de Ciencias Sociales, que a su vez sirven como insumo para la elaboración de la malla curricular institucional de la misma área y, por el otro, estas experiencias se encuentran muy permeadas por la concepción que asume o establece la docente con respecto a la enseñanza de las Ciencias Sociales, según su formación profesional y subjetividad política.

Cada actividad, dinámica o experiencia propuesta en el aula es planteada por la docente con el fin de alcanzar unos objetivos que surgen, como se mencionó antes, a partir de unos parámetros curriculares, pero que además se plantean y proyectan de acuerdo con las concepciones que asume cada docente dentro del aula. Por ejemplo, en este ejercicio se puede evidenciar el caso de la docente de grado tercero quien manifiesta que su interés para la enseñanza del área está basado en la formación de lo político, cuya apuesta se sale del marco de las temáticas tradicionalistas, ya que su interés está dirigido a que el estudiante se conciba como sujeto partícipe a partir de categorías como gobierno, sociedad, ciudadano. Es decir, la docente establece para este grado una propuesta de trabajo que ella denomina "políticos" y lo describe como un acercamiento a la categoría de lo político, pero a partir de escenas o dibujos animados como la princesita Sofía, Bajo terra o Gokú en la antesala a la gran batalla. Desde la concepción de lo político es posible, según la docente, que el niño(a) se consolide como un sujeto capaz de comprenderse como ser político. "Mi enseñanza apunta a una formación de lo político", afirma la docente de grado tercero. Así, se proyecta una perspectiva de enseñanza diferente ya que el concepto político no es un tema que se aborde en estos grados, generalmente las temáticas allí planteadas se desarrollan alrededor del reconocimiento del entorno, geografía y algunas relacionadas con la historia como la Colonia, Conquista y los primeros pobladores.

Desde las experiencias de aula propuestas por las docentes de primero y segundo de primaria se logran vincular categorías que directa o indirectamente demarcan concepciones que también van configurando determinadas formas de subjetivación. Es preciso señalar que cada experiencia que se proyecta en el aula va determinando en los estudiantes ciertas nociones que aportan en la consolidación de su pensamiento, desde donde es posible una configuración de subjetividad política.

La escuela, como uno de los escenarios de interacción, es el espacio donde se agencian experiencias, situaciones y discursos que permiten el establecimiento de configuraciones propias o colectivas que aportan a la construcción del sujeto desde un sentido físico, corporal y cognitivo que lo significa al asumir ciertas formas de pensamiento.

Este además se perfila como espacio de socialización, y es a partir de la finalidad y objetivos que se plantean dentro del aula que se puede dar un horizonte diferente a la configuración de subjetividades para tomar distancia de aquellas que se pretenden desde un marco estatal, o aquellas que vienen arraigadas desde la cultura y tradición. Es el docente quien tiene en sus manos el poder para establecer construcción de subjetividades que conlleven al niño y la niña a pensarse como sujetos activos, participes, que se cuestionen frente a su realidad social; es decir, es la posibilidad de que el docente asuma a estos niños y niñas como sujetos políticos a partir de las interacciones y construcciones que elabora desde sus actividades y experiencias cotidianas.

\section{Referencias}

Alzate, M. (2002). Concepciones e imágenes de la infancia. Revista de Ciencias Humanas, 28.

Aries, P. (1987). El niño y la vida familiar en el antiguo régimen. Madrid: Taurus.

Bustelo, E. S. (2007). El recreo de la infancia, argumentos para otro comienzo. Buenos Aires: Siglo XXI.

Caillois, R. (1997). Los juegos y los hombres. La máscara y el vértigo. México: Fondo de Cultura Económica. 
Carli, S. (2006). La cuestión de la infancia entre la escuela, la calle y el shopping. Buenos Aires: Paidós.

Congreso de la República de Colombia. (1968). Ley 75. Por la cual se dictan normas de filiación y se crea el instituto de Bienestar familiar.

Congreso de la República de Colombia. (2006). Ley 1098. Código de infancia y adolescencia.

Díaz, A. (2009). Sara Victoria Alvarado. La producción de conocimientos sobre subjetividad política desde los jóvenes: aportes conceptuales y metodológicos. Cuadernos del Cendes, 26(70), 127-140.

Díaz, A.; González, F. (2012). Subjetividad política y psicologías sociales críticas en Latinoamérica: ideas a dos voces. Universitas psichologica, 11(1), 325-338.

González, M. (2012). La agencia de la niña y el niño en la condición pre-ciudadana. Actualidades Investigativas en Educación, 12(2), 1-19.

Hernández, O. G. (2008). La subjetividad desde la perspectiva histórico-cultural: un tránsito desde el pensamiento dialéctico al pensamiento complejo. Revista Colombiana de Psicología, 17, 147-160.

Jiménez, A. (2012). Emergencia de la infancia contemporánea 1968-2006. Bogotá: Universidad Distrital Francisco José de Caldas.
Kant, I. (enero, 2010). ¿Qué es ilustración? Atrévete a saber, atrévete a pensar.

Kaufman, S. (2006). Lo legado y lo propio. Lazos familiares y transmisión de memorias. En: E. Jelin y S. Kaufman (comps.), Subjetividad y figuras de la memoria. Buenos Aires: Siglo xxı.

MacNaughton, G.; Hughes, P.; Smith, K. (2007). Young children's, rights, public policy: practices and possibilities for citizenship in the early years. Children \& Society, 21(6), 458-469. DOI: https:// doi.org/10.1111/j.1099-0860.2007.00096.x

Martínez, B. (s.f.). La representación del cuerpo del niño. Inédito.

Ministerio de Educación Nacional de Colombia (MEN). (2006). Estándares básicos de competencias en Ciencias Sociales. Bogotá: MEN.

Muñoz, C.; Pachón, X. (1996). La aventura infantil a mediados de siglo. Bogotá: Planeta.

Narodowski, M. (1994). Infancia y poder. La conformación de la pedagogía moderna. Buenos Aires: Aique.

Peña, N. C. (2015). La enseñanza de la historia y la construcción de subjetividad política de niños y niñas de básica primaria (Tesis de Maestría). Universidad Pedagógica Nacional.

Postman, N. (1982). The Disappearances of Childhood. Nueva York: Dell Publisher. 